will use the flour, are mostly the 'quality' native varieties like Yeoman and Holdfast, while the farmer prefers the higher-yielding, stronger-straw varieties like Cappelle Desprez and Bersee, and the Frenchtype Hybrid 46 bred in Britain. Occasionally the apparently conflicting requirements are reconciled, as in the variety Atle, while, as in barley, hope for further reconciliation was expressed in the characteristics of new hybrids. Mr. D. G. Bullard put the farmers' point of view, and questioned, as did most farmers present, whether the millers would be prepared to pay an adequate premium for grain quality to compensate for the lower yield of the varieties of accepted quality that are available.

As in the case of barley and sugar beet, the wheat problem was left for the plant breeder to resolve as best he can. The conference brought out most clearly the demand and necessity for further improvement in the varieties of the three crops. The scientific problems posed by such continuous improvement are varied, and the work of improving, testing and sifting the plant material is the foundation of a progressive crop husbandry.

The chairman on the first day of the Conference was Mr. Roland Dudley, and on the second day Mr. Samuel Taylor. Dr. G. D. H. Bell summed up the proceedings on both days.

G. D. H. BELI

\section{ANALOGUE AND DIGITAL COMPUTERS}

\section{PROCEEDINGS OF THE WESTERN COMPUTER CONFERENCE}

$\mathrm{T}$ HE proceedings of the 1953 Western Computer Conference, held during February $4-6$ at Los Angeles, California, under the joint sponsorship of the Institution of Radio Engineers, the American Institute of Electrical Engineers and the Association for Compuiting Machinery, has now been published* and contains the full text of the technical papers and of the panel discussion, together with résumés of the four addresses, presented at the Conference. The papers were concerned with the application of computers to the handling of business data and to aircraft design and with recent developments in analogue and digital computing equipment. The subject of the discussion was "An Evaluation of Analog and Digital Computers", and the panel of four experts, under the chairmanship of Prof. G. D. McCann, of the California Institute of Technology, consisted of Dr. J. L. Barnes, a mathematician and engineer, Mr. F. Steele, vice-president of Digital Control Systems and an engineer, Dr. L. Ridenour, formerly a nuclear physicist and now vice-president of the International Telemeter Corporation, and Dr. A. W. Vance, an electronics engineer of the Radio Corporation of America.

The addresses were delivered by Dr. Simon Ramo, of the Hughes Aircraft Company, Dr. R. D. Huntoon, of the National Bureau of Standards, Dr. Lee A. DuBridge, president of the California Institute of Technology, and Dr. J. E. Hobson, director of the Stanford Research Institute. Dr. Ramo dealt with the impact of computer development on the training * Proceedings of the Western Computer Conference held by the
Joint IRE-AIEE-ACM Computer Conference Committee California, February 4-6, 1953. Pp. 231. (New York: Institute of Radio Engineers, Inc., 1953.) 3.50 dollars. and utilization of engineers. He maintained that the development of computers is work which may soon be engaging the greatest number of engineers and scientists ; specially trained graduates with a knowledge of the physical sciences (with emphasis on electronies), the workings of the human brain and business and industrial procedures in addition to government and labour regulations are required, and industry must particularly avoid large programmes until such capable technical experts are available. Dr. Huntoon discussed the factors influencing the effective use of computers and coined the word "psycho-numerosis" to describe the problem of matching computing machines to the needs of research workers. He suggested that "electronic brains", like human brains, in the process of evolution must adapt themselves to their environment in order to survive and prosper.

The complex problem of scientific man-power was the subject of Dr. DuBridge's address. He outlined the salient factors which affect the supply and demand of scientists and engineers and suggested measures to remedy the present inadequate supply. Finally, Dr. Hobson, in an address entitled "New Equations for Management", reviewed the various new factors which the complexity of industrial operations have introduced and indicated how the facts produced by applied research may be properly presented to and utilized by the managements of industrial concerns.

The eighteen technical papers were presented in four sessions. The first and second sessions were devoted to applications of computers to commercial and to aircraft design problems, respectively. The third and fourth sessions dealt with more specific technical problems in the design and use of particular sections or types of computers and included papers on the 'Nordsieck' computer; the new laboratory for three-dimensional guided missile simulation devised by the Reeves Instrument Corporation, New York; an improved cathode-ray tube storagesystem; ferroelectrics as a memory element for digital computers; and the solution of partial differential equations by difference methods using the electronic differential analyser.

\section{METEOROLOGICAL OFFICE}

\section{ANNUAL REPORT FOR 1952-53}

$T$ HE Meteorological Office has the task of meeting the civil and Service (except naval) requirements of Great Britain for meteorological information of all kinds and of improving by research its ability to meets those needs. A feature of the report of its work during the year April 1, 1952-March 31, 1953*, is that during this period the organization for the provision of weather forecasts and other information was extended. One example of this was the application to the east coast as a whole after January 31 , 1953, of the system of special warnings of meteorological situations known to be associated with coastal flooding, which had been applied successfully to the River Thames in London for many years. Experiments in the transmission by facsimile equipment to selected out-stations of charts drawn at the Central Forecast Office were begun with the view of im-

- Annual Report of the Director of the Meteorological Office for the Year April 1, 1952, to March 31, 1953. (M.O. 573.) Pp. 56. (London: H.M.S.O., 1953.) 28. net. 